\title{
PHYSICS
}
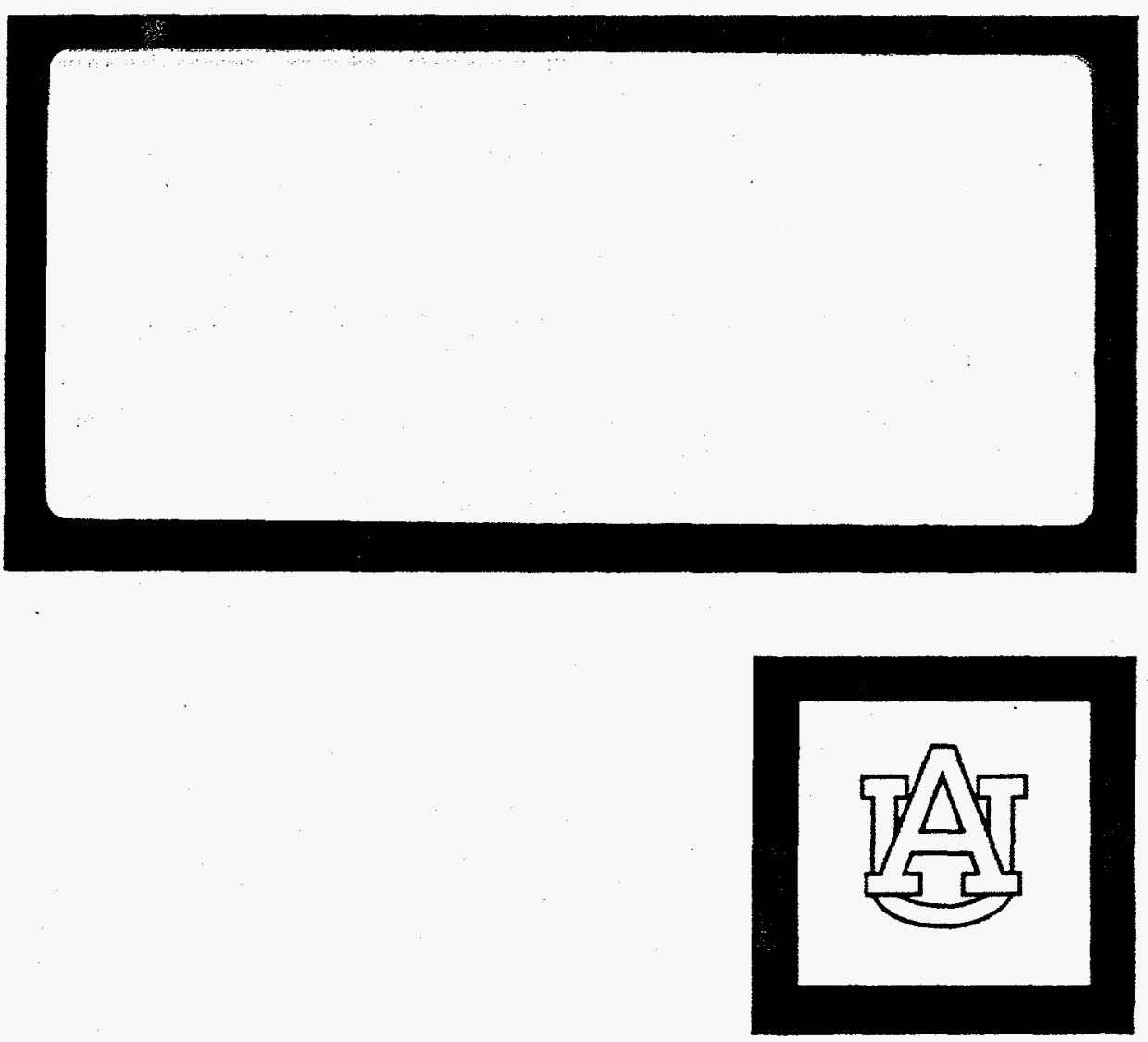

AUBURN UNIVERSITY

AUBURN, ALABAMA 


\title{
DOE/ER/53206--23
}

\section{TPX CORRECTION COIL STUDIES}

\author{
JAMES D. HANSON ${ }^{\dagger}$
}

$\dagger$ Physics Department, Auburn University, Auburn, Alabama 36849-5311

ABSTRACT. Error correction coils are planned for the TPX (Tokamak Plasma Experiment) in order to avoid error field induced locked modes and disruption. The FT (Fix Tokamak) code is used to evaluate the ability of these correction coils to remove islands caused by symmetry breaking magnetic field errors. The proposed correction coils are capable of correcting a variety of error fields.

\section{November 1994}

\section{DISCLAIMER}

This report was prepared as an account of work sponsored by an agency of the United States Government. Neither the United States Government nor any agency thereof, nor any of their employees, makes any warranty, express or implied, or assumes any legal liability or responsibility for the accuracy, completeness, or usefulness of any information, apparatus, product, or process disclosed, or represents that its use would not infringe privately owned rights. Reference herein to any specific commercial product, process, or service by trade name, trademark, manufacturer, or otherwise does not necessarily constitute or imply its endorsement, recommendation, or favoring by the United States Government or any agency thereof. The views and opinions of authors expressed herein do not necessarily state or reflect those of the United States Government or any agency thereof. 


\section{DISCLAIMER}

Portions of this document may be illegible in electronic image products. Images are produced from the best available original document. 


\section{INTRODUCTION}

The proposed Tokamak Physics Experiment (TPX) underwent a conceptual design review ${ }^{1}$ in early 1993 . Error field correcting coils will be necessary to avoid error field induced locked modes and disruption on TPX. Here we study the efficacy of the proposed correction coils in actually correcting shifts and tilts of the poloidal field coils.

The non-axisymmetries in the magnetic field, caused by shifts or tilts of the poloidal field coils, interact with the plasma most strongly by means of the creation of magnetic islands at integer $\mathrm{q}$ values. The $\mathrm{q}=2$ surface is particularly important, because of the combination of its low $m$ number and its position close to the plasma edge. The magnetic islands are caused by that portion of the non-axisymmetric field which is resonant with the background magnetic field, and which is perpendicular to the unperturbed flux surface.

The FT (Fix Tokamak) code computes the island-causing contribution of nonaxisymmetric magnetic fields ${ }^{2}$. The code treats non-axisymmetric fields from both shifted and tilted poloidal field coils and from correction coils. By imposing the criterion that the sum of the error fields and the correction coil field give a zero island-causing contribution at selected rational surfaces, the currents in the correction coils can be computed.

In this report, we compute the correction coil currents necessary to correct tilts and horizontal shifts of the poloidal field coils, for three correction scenarios. The correction coils are filamentary models of the proposed window-pane coils ${ }^{1}$. The use of windowpane coils as correction coils is a new capability of the FT code.

It is important to realize that the FT code uses a small number of circular coils to model the plasma current. Thus, there is no plasma current response considered in computing island sizes, and the q profile is inaccurate. However, the inaccuracy in the q profile is not large near the plasma edge, where the important resonant surfaces are. Also, including the self-consistent plasma response would require a much larger computational effort, using a three dimensional equilibrium code. The FT code accurately computes the magnetic field of the window-pane correction coils, and the shape and poloidal flux angle of the resonant flux surfaces. 



\section{RESULTS}

In addition to the equilibrium and correction coil information described above, the FT code needs information about 1) which correction coil currents to try to fix the error with, 2) which Resonant Perturbation Amplitudes (RPAs) to fix, and 3) the symmetry-breaking error magnetic field.

The correction coil currents are parameterized with Fourier harmonics in the toroidal direction,

$$
I_{c i}^{j}=\sum_{n} A_{n}^{j} \cos \left(n \varphi_{c i}\right)+B_{n}^{j} \sin \left(n \varphi_{c i}\right)
$$

where $I_{c i}^{j}$ is the correction coil current of the ith coil in the jth coil set, and $\varphi_{c i}$ is the toroidal angle of the center of the ith coil. Since each coil set has only four coils, the coefficients $A_{0}, A_{1}, B_{1}$, and $A_{2}$ completely determine the coil currents for each set. The odd-n constraint implies $A_{0}=A_{2}=0$ for each coil set. Thus, there are two parameters available for each coil set, for a total of six parameters. All six parameters are used for the optimizations.

A Resonant Perturbation Amplitude (RPA) is related to the Fourier amplitude of the perturbation magnetic field perpendicular to an equilibrium flux surface ${ }^{2}$. The equilibrium flux surface chosen is the one that resonates with the particular Fourier Amplitude. For example, the $\mathrm{q}=2$ flux surface is used for the computation of the $m=2$, $\mathrm{n}=1 \mathrm{RPA}$. The RPA can be readily related to an island width, if the assumption is made that only one RPA is responsible for the island. The island width is proportional to the square root of the RPA.

The choice of which RPAs to minimize greatly affects the optimization. Roughly speaking, each RPA requires two correction coil current parameters to minimize it, since an island can have an arbitrary phase. The numerical procedure for the minimization is a pseudo-Newton method using singular value decomposition. If there are more parameters (correction coil currents) available than needed for the RPAs chosen, the algorithm additionally minimizes the currents in the correction coils. If there are fewer parameters than needed for the RPAs chosen, the chosen RPAs will not be zero, but will be minimized. 

in coils sets 1 and 2 are not the same. This is a reflection of the lack of up-down symmetry in these two coil sets. Correction coil set 2 , which has smaller coils than set 1 , requires larger currents than correction coil set 1 only for case 4 . This is perhaps an indication that coil set 1 is larger than it need be.

Figures 1-6 show midplane surface-of-section plots of the magnetic fields for Cases 1-4. In all cases the $\mathrm{x}$ axis is the toroidal angle, which ranges completely around the machine. The $y$ axis shows the major radius $R$ of intersections of magnetic field lines with the midplane. Figure 1 corresponds to Case 1, where there is an error field, but no correction. Note the substantial islands visible at $\mathrm{q}=1,2$, and 3 .

Figure 2 corresponds to Case 2, where the $(2,1)$ RPA has been eliminated. In this plot, only surfaces near the $q=1,2$, and 3 surfaces are shown. The other surfaces are similar to those of Figure 1. Note the lack of a visible island near the $q=2$ surface

Figure 3 shows a radially narrow $(1 \mathrm{~cm})$ region near the $q=2$ surface, for Case 2 . Note the $(6,3)$ island present at the $q=2$ surface, with a size consistent with that given in Table IV.

Figure 4 corresponds to Case 3 , where the $(2,1)$ and $(6,3)$ RPAs have been eliminated. As expected, there is no island visible near the $\mathrm{q}=2$ surface. Figure 5 also shows a radially narrow $(1 \mathrm{~cm})$ region near the $q=2$ surface, for Case 3 . Note that the $(6,3)$ island seen in Figure 3 is not visible here.

Figure 6 shows corresponds to Case 4 , where the $(2,1),(6,3)$, and $(1,1)$ RPAs have been eliminated. Note that lack of visible islands at both the $q=1$ and $q=2$ surfaces.

\section{Different Error Fields}

Different symmetry breaking error fields will cause islands of different sizes and phases, and will require different correction coil currents to correct them. In this subsection we look at a variety of different error fields: tilts of PF 1 , and $1 \mathrm{~cm}$ shifts of each of the 14 poloidal field coils.

Table $V$ is similar to Table IV, in that it shows island widths for the three optimization strategies described above. The difference is that, instead of a shift of PF1, the error field is a $1 \mathrm{~cm}$ tilt of PF1. The results, while different in detail from those described above, are similar: the RPAs chosen can be made nearly zero, more current is required to make more 


\section{ACKNOWLEDGMENTS}

Financial support was provided by the Department of Energy, through grant DE-FG0285ER53207.

\section{REFERENCES}

1 "TPX Physics Design Description, Conceptual Design Review, March 29 - April 1, 1993”, Princeton Plasma Physics Laboratory Report 93-930512-PPPL.

2 J. D. Hanson, Nucl. Fusion 34 (1994) 441.

3 Personal Communication, 8/25/94. cfs /003012/TPX/94019.pax, file 94019.001.cgm.ps:

4 Personal Communication, e-mail of 8/24/94 and 9/8/94. 

TABLE II. Correction coil set parameters, for "eyeglass" correction coil sets. There are four window-pane coils with horizontal straight legs in each correction coil set. The coils in each set are evenly space in toroidal angle.

\begin{tabular}{ccccc}
\hline Coil Set & $\begin{array}{c}\text { Inner radius } \\
\mathrm{m}\end{array}$ & $\begin{array}{c}\text { Outer radius } \\
\mathrm{m}\end{array}$ & $\begin{array}{c}\text { Toroidal gap } \\
\mathrm{m}\end{array}$ & $\begin{array}{c}\mathrm{Z} \\
\mathrm{m}\end{array}$ \\
\hline 1 & 1.4892 & 3.6292 & 0.1153 & 2.5462 \\
2 & 1.4892 & 3.1079 & 0.1153 & -2.5183 \\
\hline
\end{tabular}

TABLE III. Correction coil set parameters, for the "picture frame" correction coil set. There are four window-pane coils with vertical straight legs in this correction coil set. The coils in each set are evenly space in toroidal angle.

\begin{tabular}{ccccc}
\hline \hline Coil Set & $\begin{array}{c}\text { Radius } \\
\mathrm{m}\end{array}$ & $\begin{array}{c}\mathrm{Z} \text { top } \\
\mathrm{m}\end{array}$ & $\begin{array}{c}\text { Z bottom } \\
\mathrm{m}\end{array}$ & $\begin{array}{c}\text { Toroidal Gap } \\
\mathrm{m}\end{array}$ \\
\hline 3 & 3.7978 & 1.7442 & -1.7442 & 1.0602 \\
\hline \hline
\end{tabular}



TABLE V. Island widths and maximum correction coil currents for cases $1,2,3$, and 4. The error is a $1 \mathrm{~cm}$ tilt of poloidal field coil 1 . Island widths are given for various $\mathrm{m}$ and $\mathrm{n}$ numbers. They are computed from the RPAs, and are as measured on the outer midplane. The RPAs chosen for optimization are shown in bold face.

\begin{tabular}{|c|c|c|c|c|c|c|}
\hline \multirow[b]{2}{*}{$\underline{c}$} & \multirow[b]{2}{*}{$\mathrm{m}$} & \multicolumn{5}{|c|}{ Island Widths, m } \\
\hline & & $\mathrm{n}$ & Case 1 & Case 2 & Case 3 & Case 4 \\
\hline & 1 & 1 & $2.71 \mathrm{E}-02$ & $2.84 \mathrm{E}-02$ & $2.74 \mathrm{E}-02$ & 4.74E-08 \\
\hline & 2 & 2 & $6.56 \mathrm{E}-04$ & $6.56 \mathrm{E}-04$ & $6.56 \mathrm{E}-04$ & $6.56 \mathrm{E}-04$ \\
\hline & 3 & 3 & $2.95 \mathrm{E}-05$ & $2.32 E-03$ & $1.50 \mathrm{E}-03$ & $2.80 \mathrm{E}-03$ \\
\hline & 5 & 5 & $7.40 \mathrm{E}-08$ & $1.92 \mathrm{E}-04$ & $4.00 \mathrm{E}-04$ & $6.44 \mathrm{E}-04$ \\
\hline & 2 & 1 & $8.24 E-03$ & $6.12 E-09$ & $1.27 \mathrm{E}-08$ & $2.43 E-08$ \\
\hline & 4 & 2 & $2.55 \mathrm{E}-04$ & $2.55 \mathrm{E}-04$ & $2.55 \mathrm{E}-04$ & $2.55 \mathrm{E}-04$ \\
\hline & 6 & 3 & $8.49 \mathrm{E}-06$ & $1.18 \mathrm{E}-03$ & $1.47 \mathrm{E}-09$ & $3.94 \mathrm{E}-09$ \\
\hline & 10 & 5 & $2.09 \mathrm{E}-08$ & $4.25 \mathrm{E}-05$ & $8.46 \mathrm{E}-05$ & $3.42 \mathrm{E}-04$ \\
\hline & 3 & 1 & $7.54 \mathrm{E}-03$ & 8.35E-03 & 8.0̀9E-03 & $7.83 \mathrm{E}-03$ \\
\hline 3 & 6 & 2 & $1.43 \mathrm{E}-04$ & $1.43 \mathrm{E}-04$ & $1.43 \mathrm{E}-04$ & $1.43 \mathrm{E}-04$ \\
\hline 3 & 9 & 3 & $5.19 \mathrm{E}-06$ & $6.78 \mathrm{E}-04$ & $1.26 \mathrm{E}-04$ & $3.79 \mathrm{E}-04$ \\
\hline 3 & 15 & 5 & 8.85E-09 & $.24 \mathrm{E}-05$ & $4.12 \mathrm{E}-05$ & $1.79 \mathrm{E}-04$ \\
\hline 4 & 4 & 1 & $2.97 \mathrm{E}-03$ & $7.54 \mathrm{E}-04$ & $1.22 \mathrm{E}-03$ & $1.96 \mathrm{E}-03$ \\
\hline \multirow[t]{2}{*}{4} & 12 & 3 & $2.74 \mathrm{E}-06$ & $4.01 E-04$ & $8.98 \mathrm{E}-05$ & $2.78 \mathrm{E}-04$ \\
\hline & & \multicolumn{5}{|c|}{ Maximum Correction Coil Currents, $k A$} \\
\hline \multicolumn{3}{|c|}{ Correction Coil Set } & Case 1 & Case 2 & Case 3 & Case 4 \\
\hline & \multicolumn{2}{|l|}{1} & 0.00 & 0.70 & 6.76 & 31.52 \\
\hline & \multicolumn{2}{|l|}{2} & 0.00 & 0.55 & 4.11 & 39.37 \\
\hline & \multicolumn{2}{|l|}{3} & 0.00 & 2.38 & 0.47 & 7.66 \\
\hline
\end{tabular}





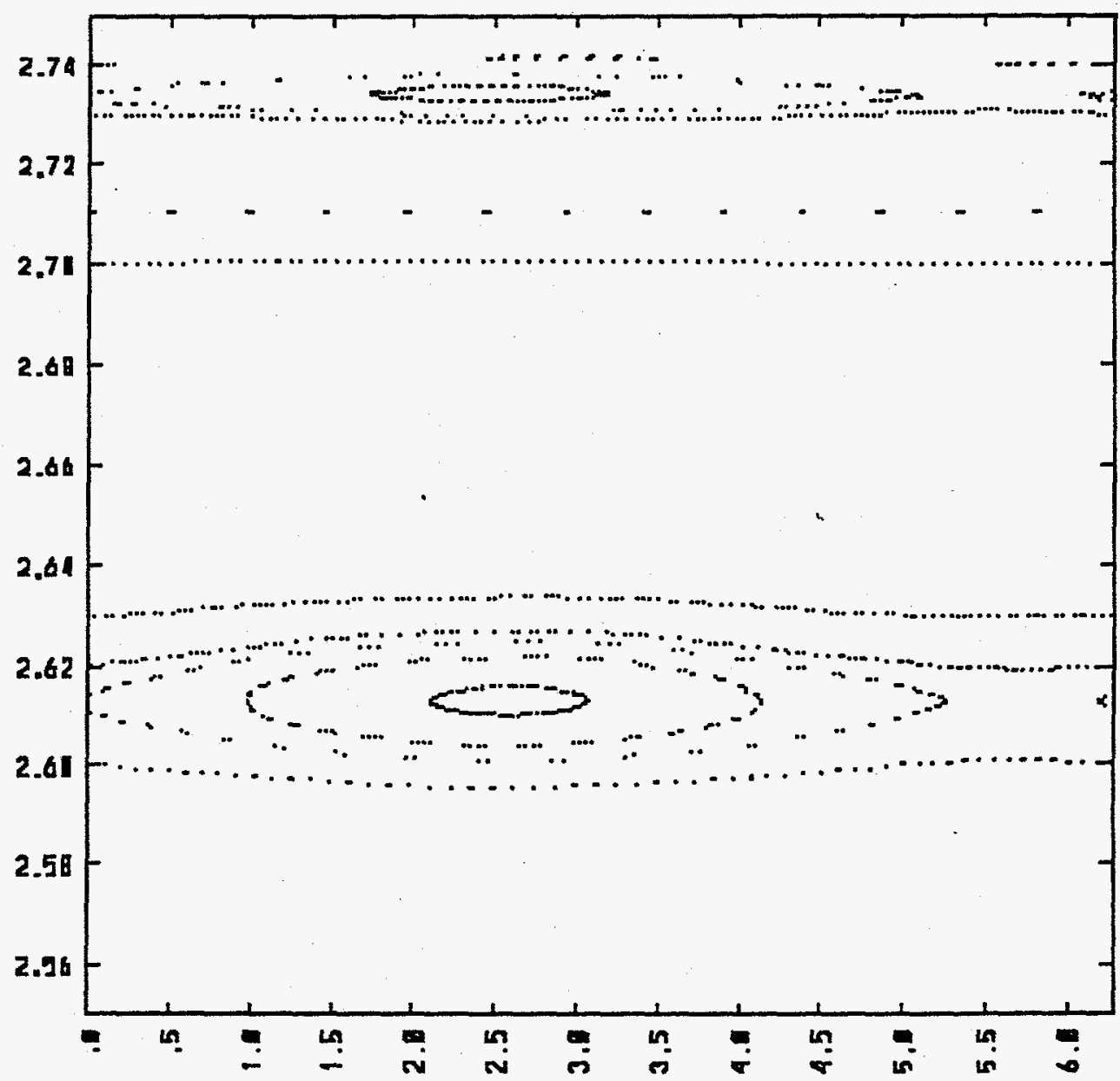

FIGURE 2. Midplane surface of section for case 2. Poloidal Field Coil 1 has been shifted horizontally by $1 \mathrm{~cm}$. Correction coil currents to minimize the $(2,1)$ RPA have been added. Note islands at the $q=1$, and 3 surfaces, and the lack of island at the $q=2$ surface. 



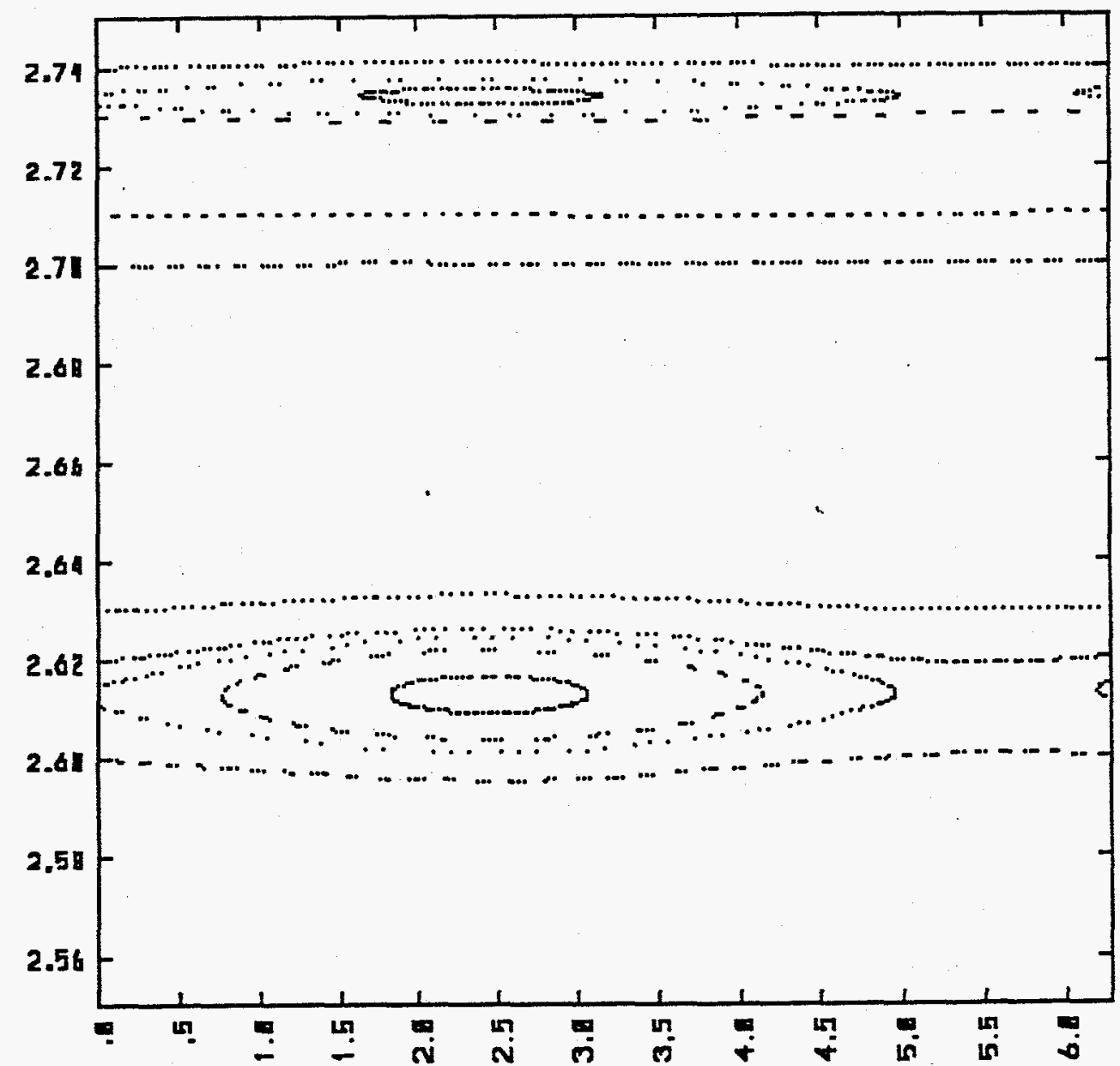

FIGURE 4. Midplane surface of section for case 3. Poloidal Field Coil 1 has been shifted horizontally by $1 \mathrm{~cm}$. Correction coil currents to minimize the $(2,1)$ and $(6,3)$ RPAs have been added. Note islands at the $\mathrm{q}=1$, and 3 surfaces, and the lack of island at the $\mathrm{q}=2$ surface. 



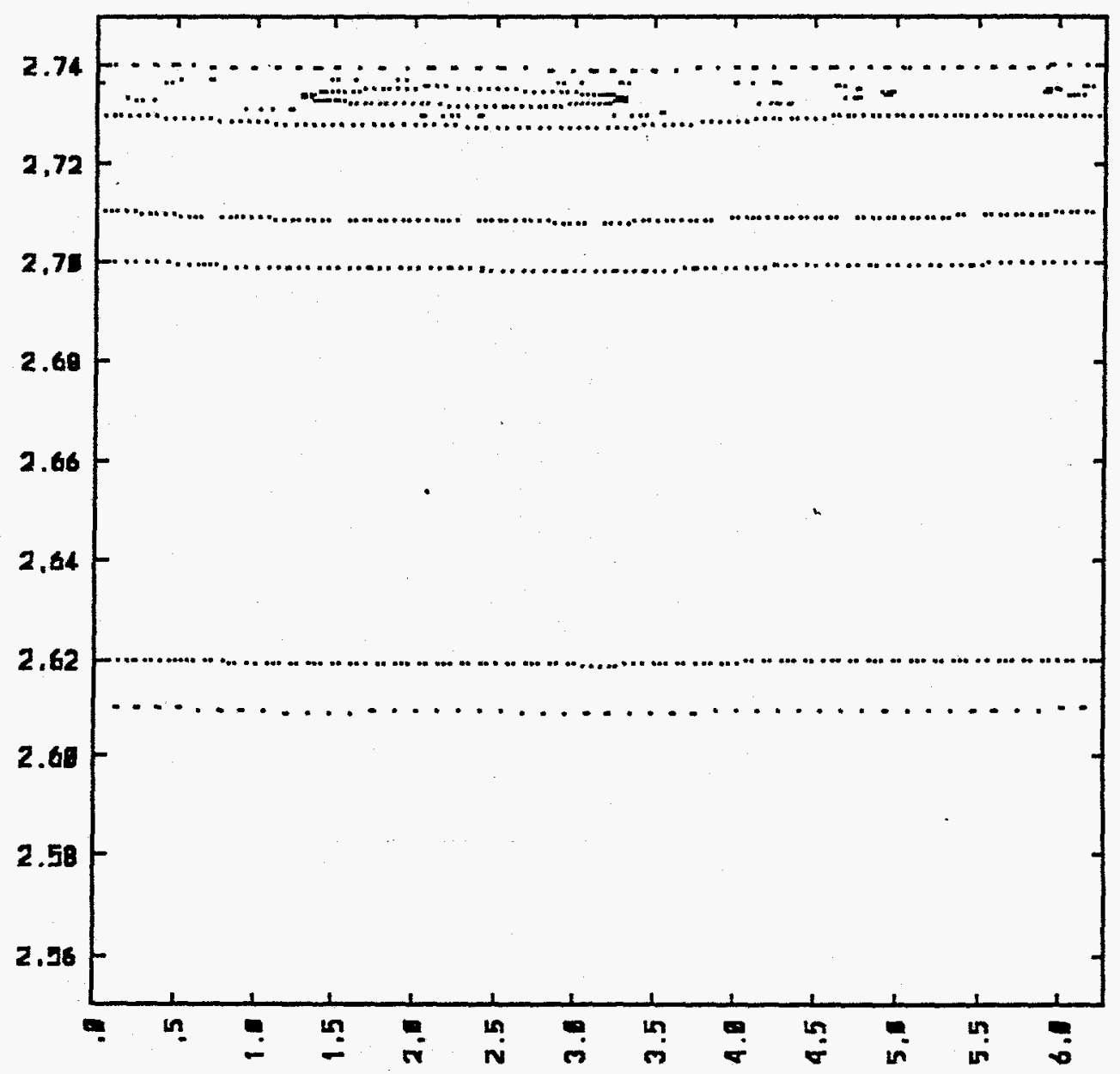

FIGURE 6. Midplane surface of section for case 4. Poloidal Field Coil 1 has been shifted horizontally by $1 \mathrm{~cm}$. Correction coil currents to minimize the $(2,1),(6,3)$ and $(1,1)$ RPAs have been added. Note the lack of islands at the $q=1$ and $q=2$ surfaces. 



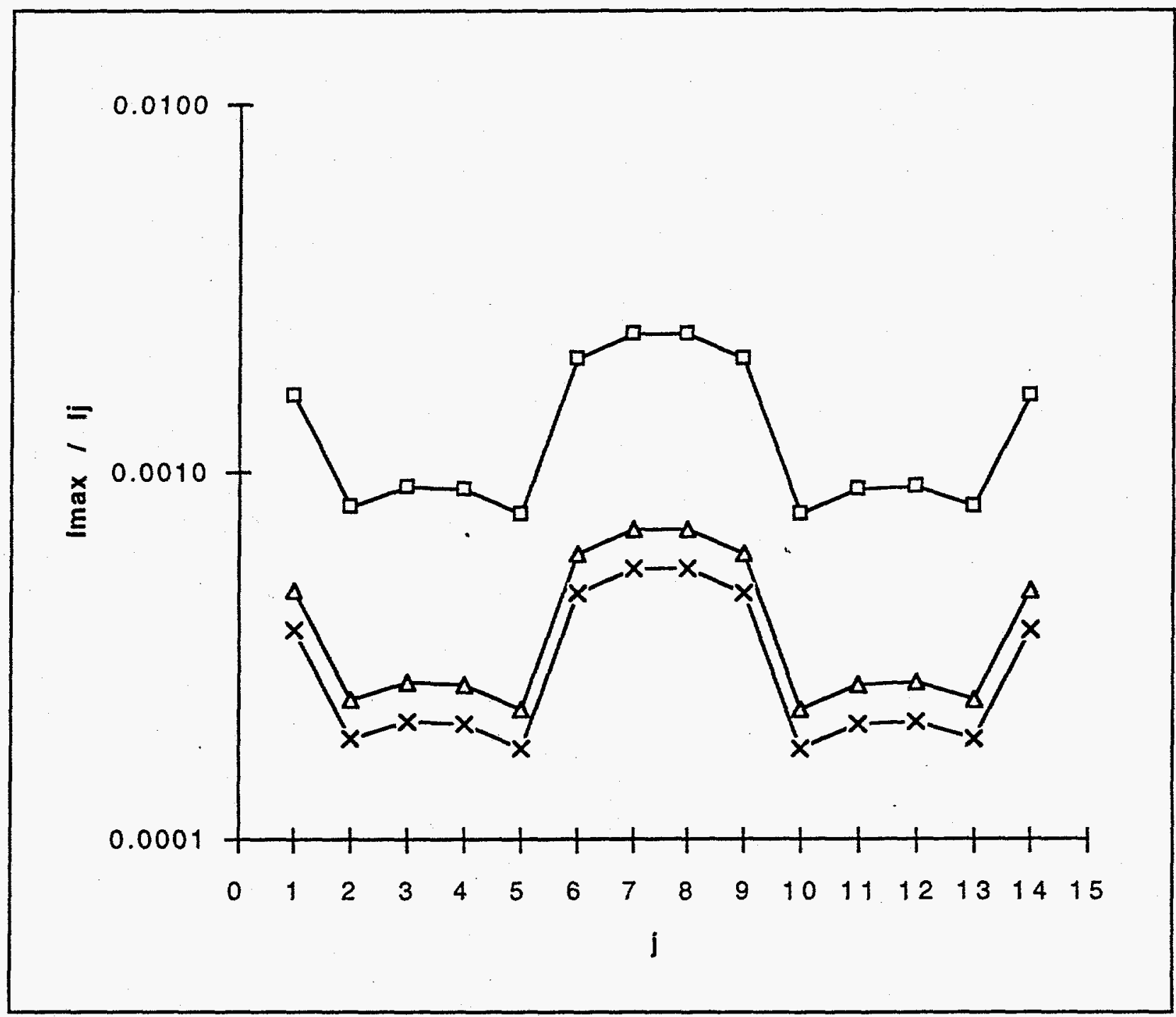

FIGURE 8. Ratio Imax to Ij vs. shifted poloidal field coil number j. Imax is the maximum correction coils current, and $\mathrm{Ij}$ is the current in the jth poloidal field coil. Triangles - coils set 1 , crosses - coil set 2 , squares - coil set 3 . 